\title{
Tests of flexible polymer joints repairing of concrete pavements and of polymer modified concretes influenced by high deformations
}

\author{
KWIECIEŃ Arkadiusz, a , GRUSZCZYŃSKI Maciej ${ }^{2, b}$ and ZAJĄC Bogusław ${ }^{1, c}$ \\ ${ }^{1}$ Institute of Structural Mechanics, Cracow University of Technology, \\ 31-155 Cracow, ul. Warszawska 24,Poland, Tel./Fax (+48 12 6282031) \\ ${ }^{2}$ Institute of Building Materials and Structures, Cracow University of Technology, \\ 31-155 Cracow, ul. Warszawska 24,Poland, Tel./Fax (+48 12 6282025) \\ aakwiecie@pk.edu.pl, bmgruszcz@imikb.wil.pk.edu.pl, cboguslaw8zajac@gmail.com
}

Keywords: Polymer flexible joints, repair method of concretes, polymer modified concretes, copolymer dispersion additive, airfield concrete pavements, high deformations.

\begin{abstract}
Three kinds of repair methods of cracked concrete floors are presented in the paper. One of them, based on coating using of polymer-cement composites, is discussed with presentation of the influence of different amount of styrene-butadiene co-polymer dispersion additive onto the shrinkage and strength. The next two correspond to injecting repair methods. There are also presented two different approaches in repair bonding of damaged floors. Following these ideas, results of testing of epoxy and polymer (PU) bonding of cracked specimens made of concrete and polymer-cement composites are discussed. Proposed new repair polymer flexible joints introduce energy dissipaters which allow protecting concrete pavements against large deformations. Presented comparisons of results indicate that the use of flexible polymers in repair process is efficient, what was confirmed by tests and observations of repair done at the KRK airport concrete pavement.
\end{abstract}

\section{Introduction}

Repair of concrete floors. In recent years there have been constructed millions of square meters of concrete floors in Poland. Their significant part need strengthening and repairs, due to long-term exploitation, the change in function or design and more frequently execution failures. Works done recently in frame of RILEM summarized defects and damages problems in floors [1] and also presented most popular methods of repair [2]. One of the new reconstructing methods is the application of thin layer of cement-polymer composites with reduced shrinkage. Such method, basing on styrene-butadiene co-polymer dispersion additive is here presented. Material and technological aspects of this method are discussed in accordance to laboratory tests results presenting the influence of different amount of co-polymer dispersion additive onto the shrinkage and strength of polymer-cement composites. It must be noticed that in some cases the surface coating of cracked floors is ineffective and new damages appears at the repaired surface (Fig. 1). 


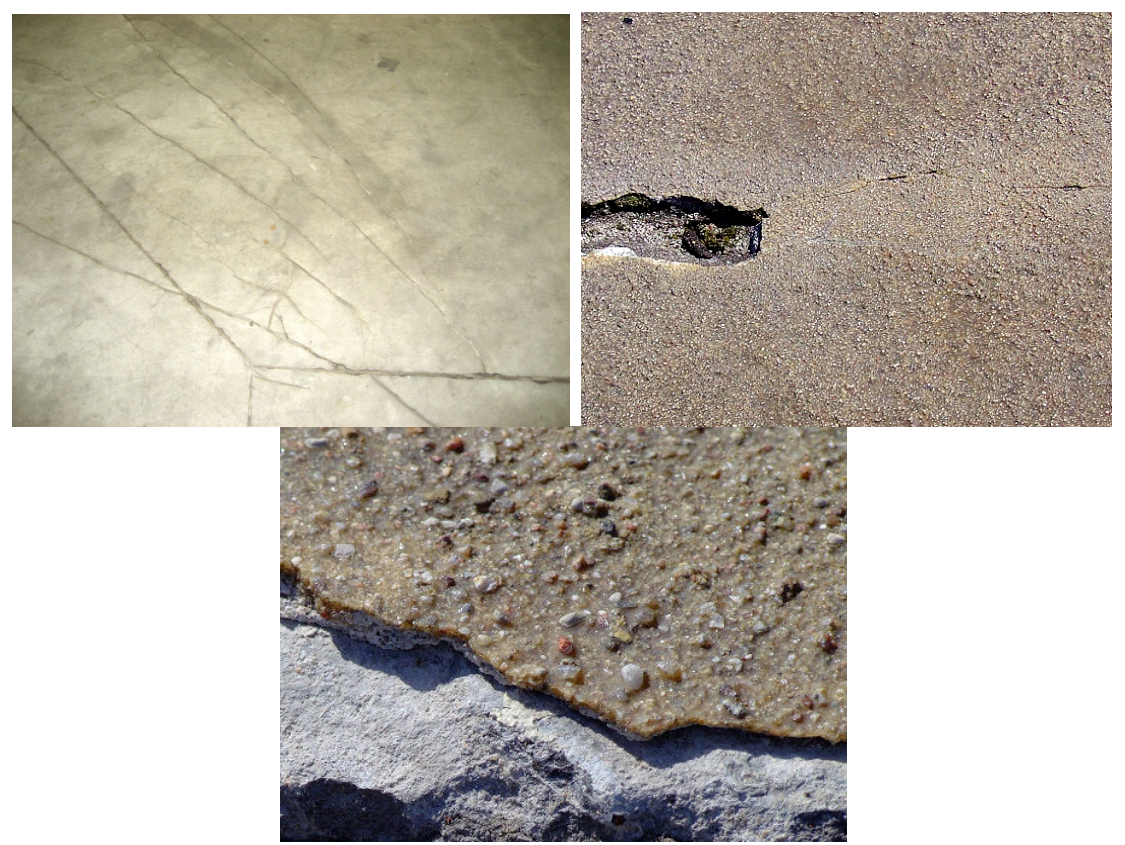

Figure 1. Damages of concrete floors covered with surface coating made of polymer-cement composites and epoxy resin, caused by high deformations

It is a sign that deep recognizing of damage causes is required and another kind of repair is needed. The Flexible Joint Method (is registered in the Polish Patent Department under No. P-368173) is proposed as an innovative method of repair of cracked concrete floors, basing on filling the cracks in damaged floor slab with flexible polymer. It results in integration of structure parts and forming the flexible joint between them, assuring the possibility of further and safe exploitation.

Repair of airfield concrete pavements. Similar damage problems touch airfield concrete pavements (highways also) that are constructed as jointed plain pavements, do not containing any steel reinforcement (Jointed Plain Concrete Pavements - JPCP). JPCP damages manifest mainly in form of various kinds of cracks, what has been discussed in [3]. They appear due to overcoming of concrete tensile strength [4] caused by complex acting of loading stresses, warping stresses due to temperature differential and stresses due to sub-grade restrain [5]. Sporadically, they are caused by very rapid heating and cooling processes due to high-temperature exhaust gas from vectored thrust engines [6]. Inappropriate design and construction of joints and sealants filling joints in rigid pavements are often the cause of damage in concrete slabs (Fig. 2a). The presented damages are caused directly by stress concentration acting locally due to slab pressure [7]. There are many methods of repair concrete pavements but in most cases the problem is repair time. Impossibility of closing of an airfield pavement and often very short break time (3-4 hours) force using of rapid repair methods. 
Typically, rapid repair of main cracks in slabs is realized using bituminous masses covering only the damages. Unfortunately, this kind of protection is ineffective just after few months of exploitation, because the degraded mass (Fig. 2b, 2c) allows for infiltration of water under slabs [8]. The coming into being hydrodynamic pump effect (due to moving loads - Fig. 3a) destructs sealants in joints (Fig. 3b) and causes uneven settlement of concrete slabs (Fig. 3c). The solution of this problem is the use of special polymer flexible joints.
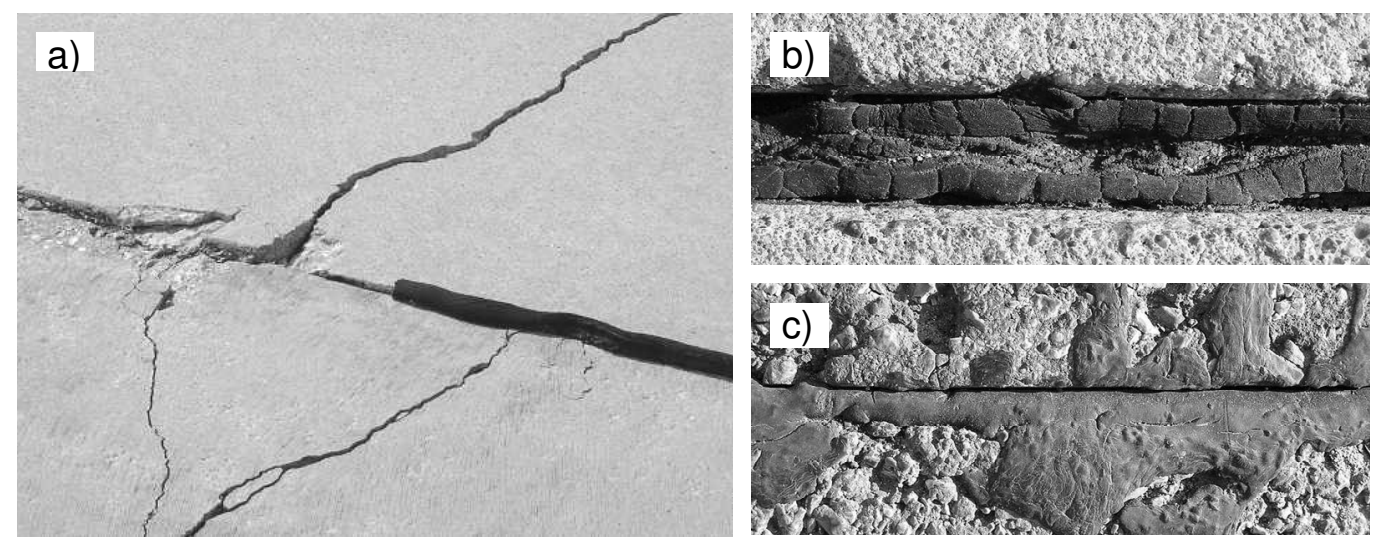

Figure 2. Damages of airfield concrete pavement caused by stress concentration due to slab pressure (a) and degradation of bituminous mass filling contraction joints (b, c)
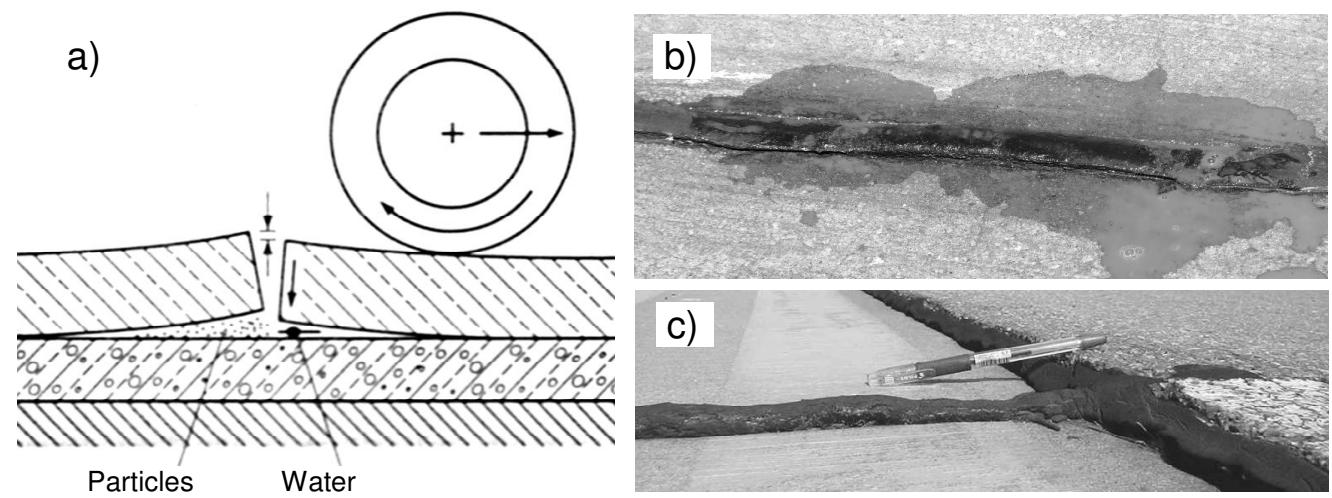

Figure 3. Scheme of the hydrodynamic pump effect (a) and caused by it damages of bituminous sealant $(b, c)$ and the vertical movement of concrete slab forming fault (c)

\section{Polymers as construction material}

Change in bonding and construction philosophy. In the past, stiff polymer adhesives of high shear and tensile strength (up to $30 \mathrm{MPa}$ ) as epoxy resin were preferred in bonding and repair applications. Unfortunately, these kinds of materials have low ultimate strain of range under 4\%, thus are inconvenient in bonding of brittle materials as concrete where high deformability or dynamic action is expected. On the other hand, flexible polymers of elastomeric behavior as polyurethane mass (PU) have ultimate strength of 1 to $20 \mathrm{MPa}$ but ultimate strain of 10 to $1000 \%$. Adhesive joints made of polyurethanes characterize higher value of deformation energy and ductility than epoxies, what can be measured by area under the curves of $\sigma-\varepsilon$ characteristics [9].

These properties of flexible polymers are utilized widely in marine and transportation construction and have been started using as structural building materials in civil engineering $[10,11]$. Polymer flexible joints represent new philosophy in repair of cracked structural elements made of brittle materials as concrete or masonry, working in a different way than stiff kinds of repair joints, widely used up to now. Flexible repair joints allow for local slight deformation absorbing or dissipating in this way strain energy and can tolerate repeated cyclic deformations without loosing of their load-carrying capacity. 
Traditionally, protection against cracking of concrete floors and the rigid JPCP demands that a concrete pavement must be of enough thickens. This requirement do not allows for appearing of high value of a floor or a pavement deflection and thus protects concrete against overcoming of the concrete ultimate strain. In the new approach, the polymer of well-matched flexibility (applied in slab joints or in slab cracks) makes the flexible joint as a bond of cracked or not damaged structural elements. It introduces in the concrete pavement new tensile, shear and compression resistance, high waterproof ability and also increases deformability, ductility and damping of the whole structure. Flexible joints work as dissipative hinges that allow for higher but save deflection of floors or pavements (Fig. 4), assuring lower stress in slabs under load and uniform distribution of stress between slabs over the total contact surface [12].

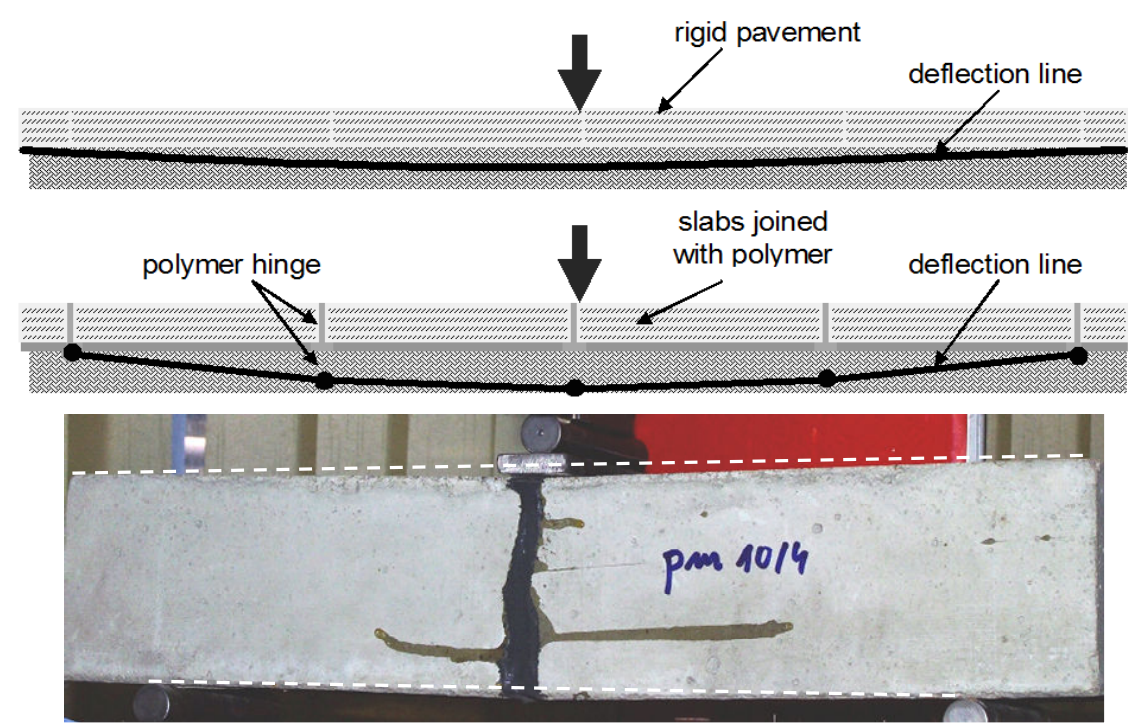

Figure 4. Schemes of work of the rigid concrete pavement and of the pavement constructed using flexible polymer joints, functioning as waterproof hinges dissipating deformation energy under the moving load, and view of deformed concrete beam repaired using of flexible polymer joint (polymer hinge)

Deformation energy of polymers, steel and concrete. Materials characterized by ultimate stress and ultimate strain in linear range can be compared using of strain energy $U$ (Eq. 1), by calculating of strain energy density W (Eq. 2). Such calculation was done for concrete C30/37, steel 34GS, hard polymer PT and soft polymer PM. Results of comparison presented graphically in Fig. 5 showed that presented flexible polymers made of polyurethane mass PU have enough ability to absorb deformation energy and to work as a structural material [13].

$$
\begin{aligned}
& \mathrm{U}=\int_{\mathrm{V}}\left(\frac{1}{2} \sigma_{\mathrm{ij}} \varepsilon_{\mathrm{ij}}\right) \mathrm{dV} . \\
& \mathrm{W}=\frac{1}{2} \sigma_{\mathrm{ij}} \varepsilon_{\mathrm{ij}} .
\end{aligned}
$$




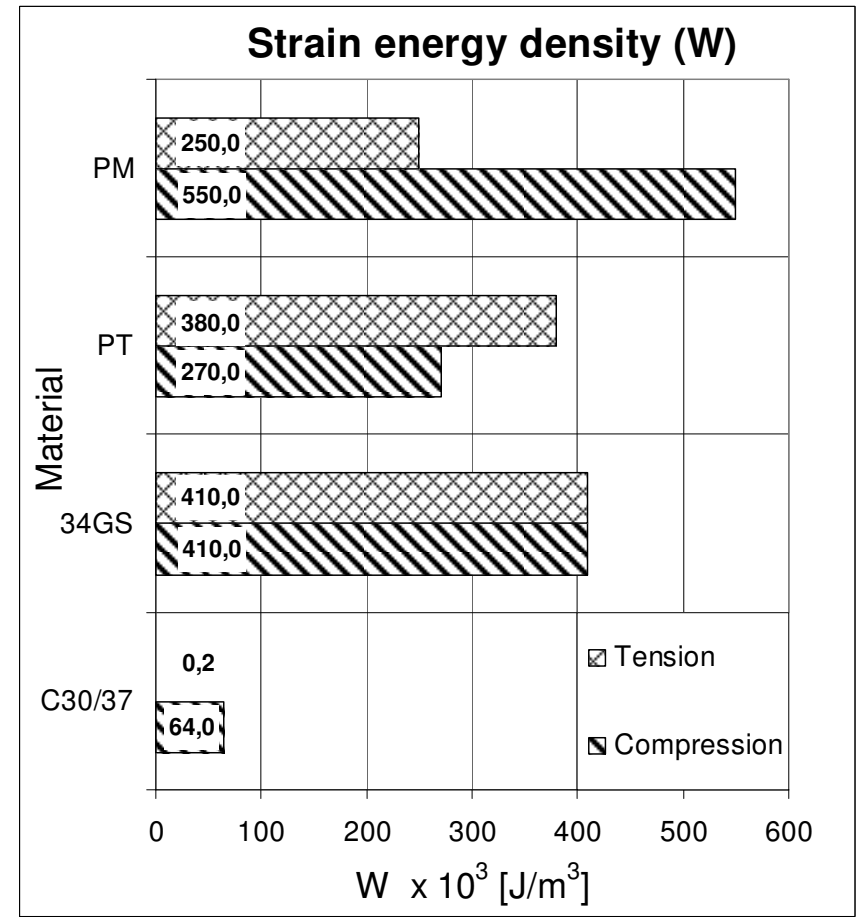

Figure 5. Comparison of strain energy density of structural materials: concrete C30/37, steel 34GS, hard polymer PT and soft polymer PM, representing enough ability to absorb strain energy of a structure

Two approaches of flexible bonding philosophy. In flexible bonding the proper selection of polymer properties is very important. The most important is modulus of elasticity which account for flexibility of a polymer joint and also polymer strength. There are exist two approaches in projecting process of flexible polymer joint.

In the first approach, the new constructed polymer joint is assumed of higher strength than bonded materials (concrete elements) but flexibility of the polymer causes reduction of stress concentration increasing the strength of original specimens after repair [14]. The confirmation of the above mentioned assumption was found during the three point bending test of a concrete specimen (C25/30). First, eight concrete beams (Fig. 6) were damaged and next they were bonded together using the hard flexible polymer PT (Young modulus $\mathrm{E}=600 \mathrm{MPa}$, tensile strength $18 \mathrm{MPa}$, adhesion to concrete $>5 \mathrm{MPa}$, elongation 10\%). The next destructive test on the repaired specimens showed that the flexible bonded concrete elements have higher strength than the original ones of about $30 \%$. It is visible in the diagram (Fig. 6), presenting the calculated ratio $r$ of the bending moments (Eq. 3) obtained during the research.

$$
\mathrm{r}=\frac{\mathrm{M}_{\text {polymer }}}{\mathrm{M}_{\text {concrete }}} \cdot 100 \% \text {. }
$$

where: $\mathbf{M}_{\text {concrete }}=$ ultimate bending moment of the original concrete specimen, $\mathbf{M}_{\text {polymer }}=$ ultimate bending moment of the polymer bonded concrete specimen. 

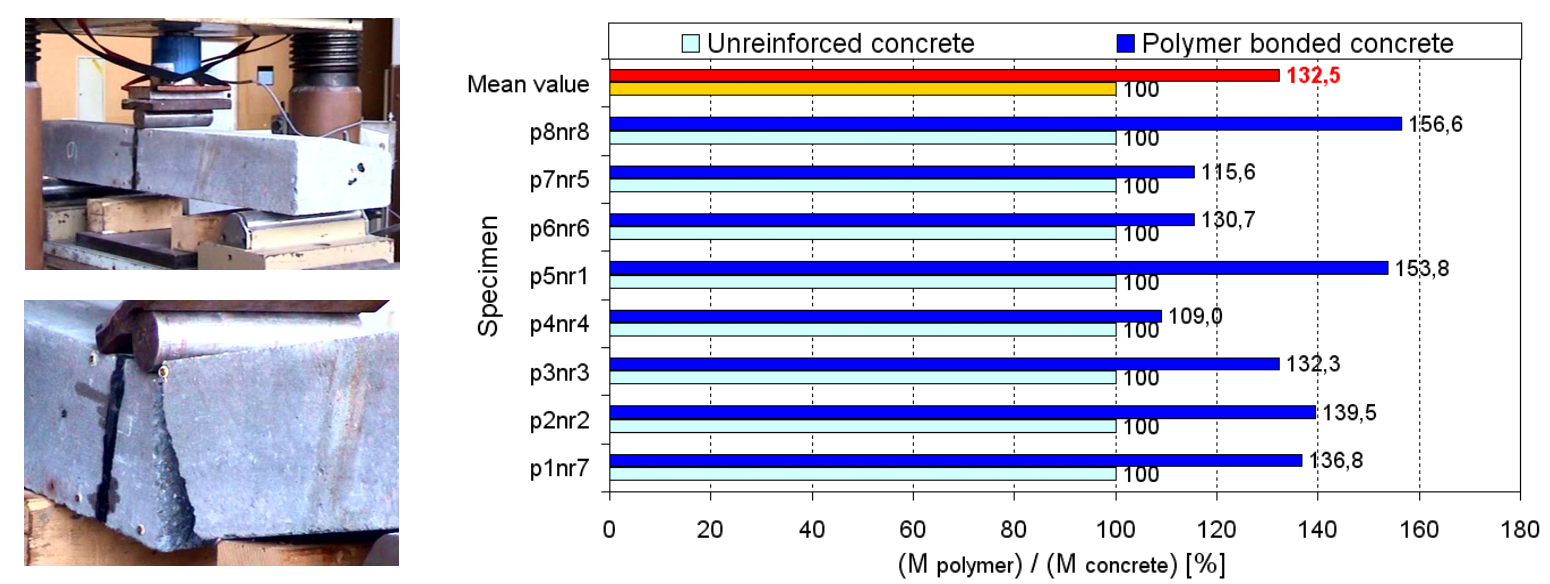

Figure 6. Three point bending test of the repaired concrete specimen using flexible polymer mass and the comparison of the strength of the original and repaired concrete specimens

In the second approach, the new constructed polymer joint is assumed of lower strength than bonded materials (Fig. 7), to assure lack of damage appearance in joined structural elements. Flexibility of polymer introduces higher deformability and thus increases amount of energy needed for destructing of the joint, which is a sum of structure and polymer deformation energy.

$\sigma_{1}$ - tensile principal stress $\quad f_{s}$ - concrete strength in tension $f_{j}$ - polymer strength in tension

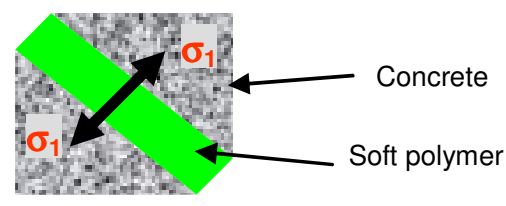

Exploitation stress after repair

$$
\sigma_{1}=0.4 f_{s}=0.6 f_{j}
$$

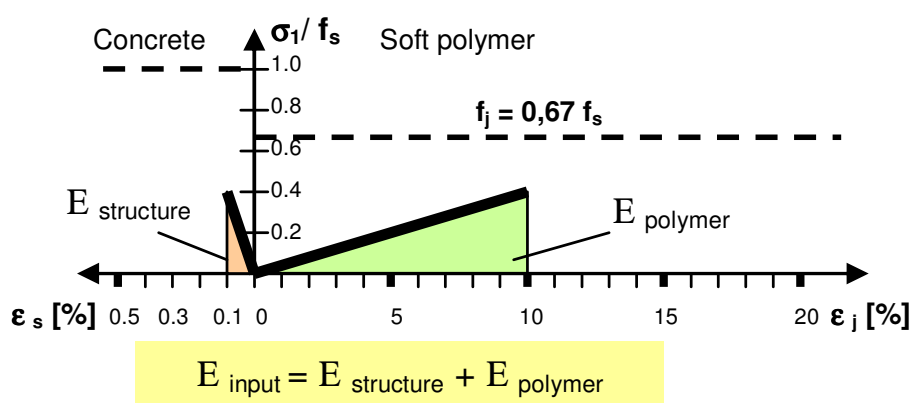

Figure 7. Graphic presentation of deformation energy, measured by area under the curves of $\sigma-\varepsilon$ characteristics, showing different deformation of a concrete structure and of polymer joint

(with the same level of stress in both materials)

\section{Material characteristic of cement-polymer composites used in tests of repair joints}

In the case of high deformations influencing a cracked floor, a reconstructing method using of thin layer of cement-polymer composites can be ineffective. New cracks appearing on the reconstructed floor surface should be repaired with deformable materials allowing for change of cracks width and carrying of loads. These requirements fulfill polymer flexible joints which were tested in cooperation with concrete specimens with polymer additive.

Influence of polymer admixture on cement-polymer composites constructing test specimens. Cement composites modified with polymer additive, as a result of the change within the structure, are characterized with the favorable altered properties in comparison with mortars and normal concretes (significant increase in tensile and bending strengths, reduction of shrinkage strains, decrease in the value of elasticity modulus, durability improvement). These advantageous properties are used in repair of defects and damages of floors, in the application of surface coating using of thin layer of cement-polymer composites with reduced shrinkage.

Application of polymer modifiers, on the level of at least 5\% of cement mass, results in the formation of continuous membrane that penetrate the cement matrix, in the change in shape and dimensions of crystals within the cement binder and in general reduction of composite porosity due 
to limitation of water. Moreover, addition of polymer dispersion causes significant tightness of contact layer between aggregate grains and paste. In composites of such type this layer is filled with directed polymer particles which increase the contact surface between the matrix and aggregate and results in tightness of inter-phase zone [15].

Tests carried out on cement-polymer composites specimens. In conducted research program for modification of concrete series there were used different amount of styrene-butadiene dispersion additive (SBR). The following levels of polymer addition dosage were used: 5, 10, $20 \%$ of cement mass. Concretes were designed on the base of CEM I 32,5R cement, assuming its application on the level of $350 \mathrm{~kg} / \mathrm{m} 3$. W/c ratio for all concrete mixes was equal to 0.50 . As control the specimens made of concrete C 30/37 without any addition of SBR (0\%) were adopted.

Shrinkage strains measurements were carried out with the application of the shrinkage gutter set $(100 \times 60 \times 1000 \mathrm{~mm})$ equipped with electronic sensors of length change Mitutoyo - Fig. 8. Applied measuring method make it possible to record the change in the samples length practically from the first moment after casting the samples and measurements are made automatically within the assumed time intervals.

Bending strength were measured in the three-point bending test on beam specimens of dimension $40 \times 40 \times 160 \mathrm{~mm}$ (distance between supports was $100 \mathrm{~mm}$ ) and compressive strength were measured in the axial compression test on specimens of dimension $40 \times 40 \times 40 \mathrm{~mm}$.

Obtained test results. Tests results univocally indicate that styrene-butadiene co-polymer dispersion additive significantly influences the magnitude of shrinkage strains (Fig. 8). Addition of styrene-butadiene co-polymer with the amount of 5 and $10 \%$ of cement mass does not change much the course of shrinkage in time. But results in significant limitation of the final shrinkage value to the level of $60 \div 70 \%$ lower than for the control concrete. Shrinkage of such composite takes less time and practically stabilizes after 10 to 14 days [16].
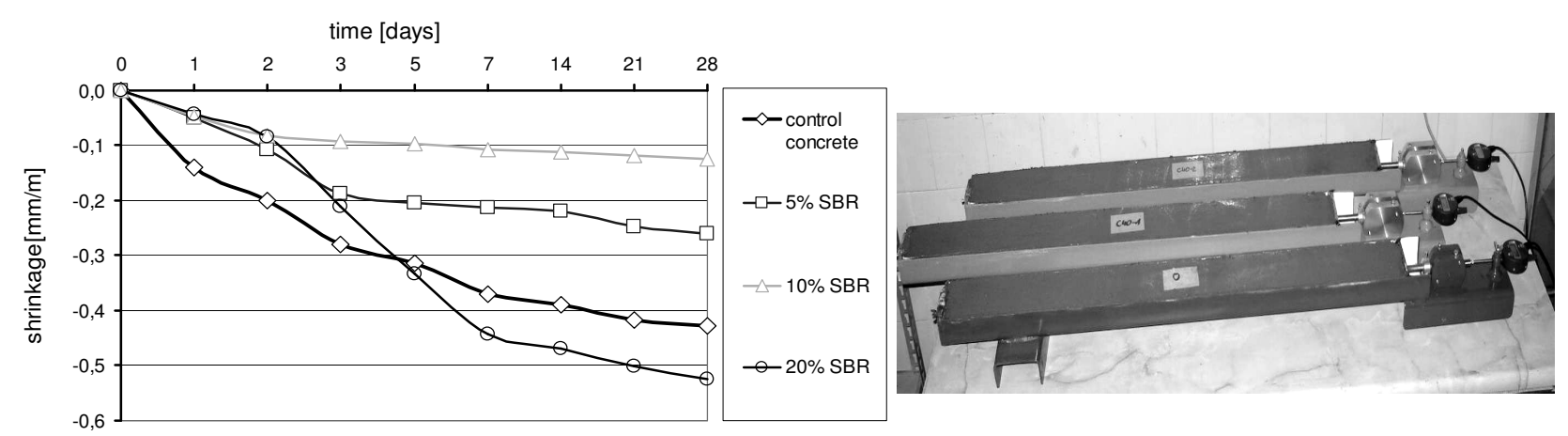

Figure 8 . The course of shrinkage for mortars modified with SBR polymer and control concrete and next view of laboratory stand for measuring of the concrete shrinkage strains

For concrete with $20 \%$ addition of SBR shrinkage takes much longer time and is greater than for concrete without polymer addition. Increase in SBR polymer addition up to $20 \%$ of cement mass results in the change in shrinkage course and after 28 days it reaches the value about $25 \%$ greater than for control concrete.

Analysis of obtained results indicates that polymer additives significantly reduce the shrinkage strains from concrete drying. It is due to penetration of cement matrix with polymer membrane that surrounds course of aggregate, cement and forms spatial structure of honeycomb type. Additional favourable effect of polymer application is the fact that polymer membranes surround the cement grains restraining the water access, thus slowing down the process of its hydration. Hydration products, in particular portlandic crystals, are characterized with favourably altered structure [17]. The other advantageous effects are the ability of polymer particles to bridge the shrinkage microcracks that occurred within the cement paste.

In Fig. 9 there are presented tests results for bending strength for concretes modified with different amount of SBR polymer after 7 and 28 days. 


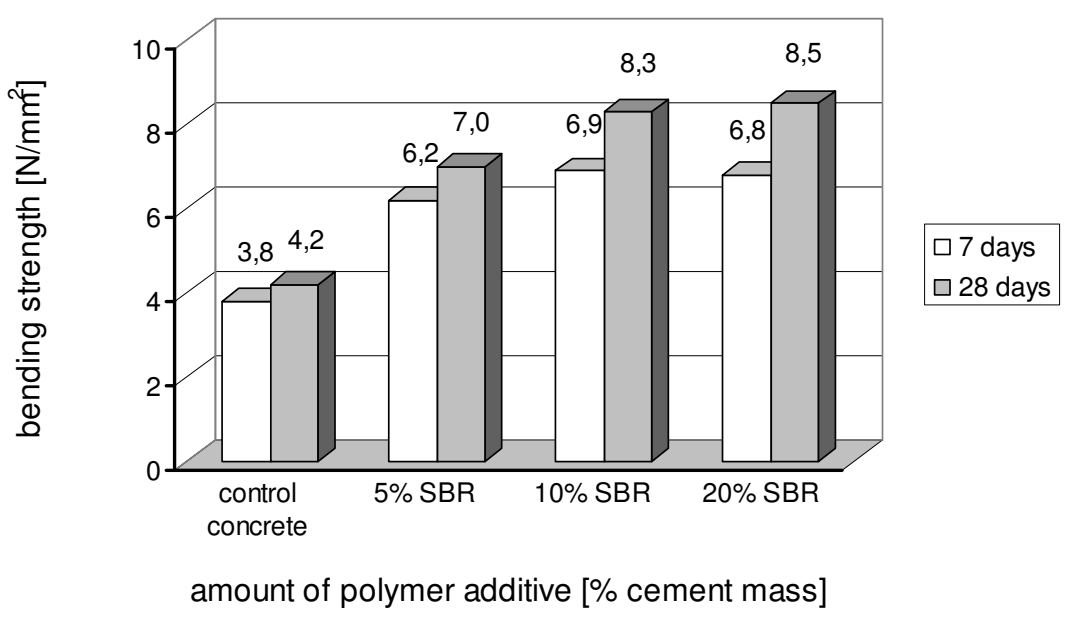

Figure 9. Influence of SBR polymer additive on bending strength of concrete after 7 and 28 days

Analysis of influence of polymer additive onto bending strength of concrete indicates that independently on the amount of applied addition the increase of strength is observed within the range of $80 \div 100 \%$ in comparison with the control concrete, both for 7 and 28 days. Increase in tensile and bending strength for mortars and concretes modified with polymers is caused by strengthening the contact zone paste-aggregate course due to porosity reduction. It is a common belief that contact zone paste-aggregate course is less porous and contains less products of hydration than the rest of paste. For the case of composite modified with polymer the voids in the contact zone are filled with polymer particles, which improves the contact between aggregate course and cement matrix [18]. The increase in bending strength is also caused by significant composite deformability improvement and ability of polymer particles to bridge the micro-cracks [19, 20].

Tests results analysis for compressive strength indicates its small changes in comparison with the control concrete after 7 and 28 days (Fig. 10). Observed small reductions of compressive strength in comparison with the control concrete are caused by delay of hydration process resulted from formation of polymer membranes and aeration effect of polymer additive that reflects in results of concrete density measurements. Application of SBR polymer additive causes reduction of compressive strength after 28 days within the range of $5 \div 10 \%$. However, the strength decrease of cement-polymer mortars may be compensated by making the use of highly fluxing effect of these additives for reducing the value of $w / c$ ratio.

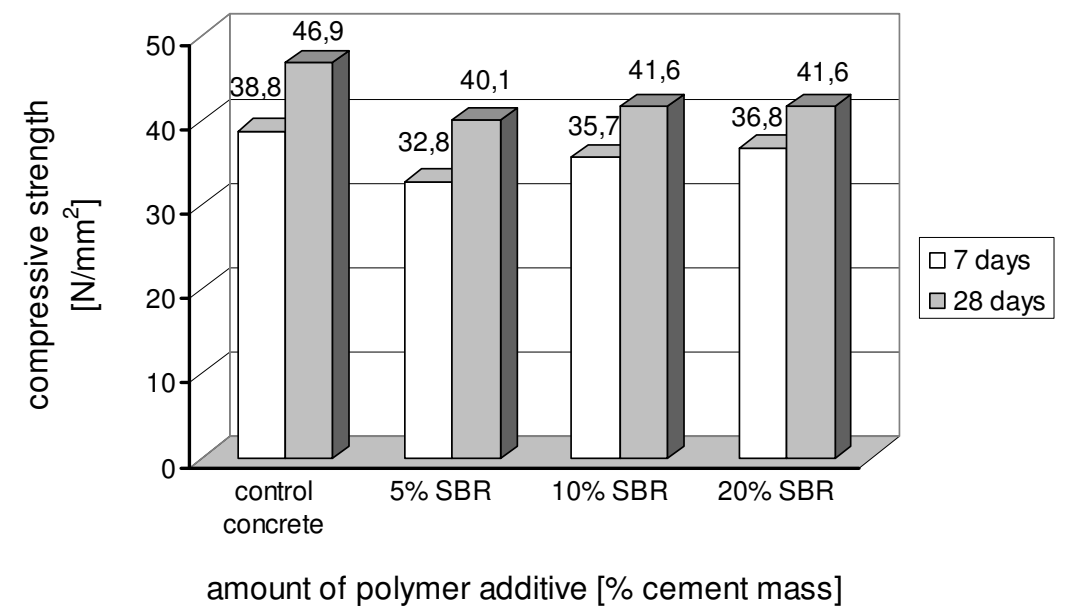

Figure 10. Influence of SBR polymer additive onto concrete compressive strength after 7 and 28 days 


\section{Repair of concrete and cement-polymer composites using of polymer flexible joints}

Tested specimens with polymer joints. The presented repair method use flexible polymers as injecting mass filling cracks of damaged concrete floors. It is assumed that polymers can repair cracked concrete and also the cracked thin repair layer made of cement-polymer composites, damaged by over-ultimate deformation. In the first approach, the epoxy resin Sikadur 53 (bending strength $49 \mathrm{MPa}$ ) and the hard flexible polymer PT of strength higher than the cement-polymer composite modified using of SBR were applied. In the second approach, the soft flexible polymer PM (elongation $140 \%$, Young modulus $\mathrm{E}=4 \mathrm{MPa}$, tensile strength $1.4 \mathrm{MPa}$, adhesion to concrete $1 \mathrm{MPa}$ ) of strength lower than control concrete C30/37 was applied.

Testing of repair method was done in concrete specimens of the beam shape of dimension $500 \times 100 \times 100 \mathrm{~mm}$, made of four materials described in the previous chapter, and realized in the three-point bending test (distance between supports was $400 \mathrm{~mm}$ ) - Fig. 11. In the first step, original concrete beams (with 0\%, 5\%, 10\%, 20\% addition of SBR) were disrupted by bending forces and after bonding in the second step were damaged once again. Six specimens made of cement-polymer composites $(5 \%, 10 \%, 20 \%$ addition of SBR - two for each case) were repaired using bonding joint of $5 \mathrm{~mm}$ width, made of the epoxy resin and of the polymer PT. Three specimens made of concrete C30/37 (0\% addition of SBR) were repaired using bonding joint of $10 \mathrm{~mm}$ width, made of the soft flexible polymer PM.
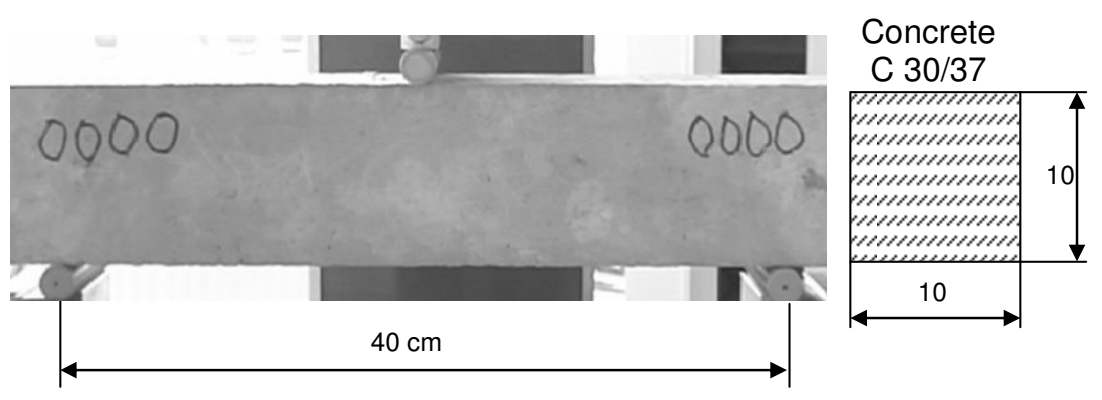

Concrete:

C $30 / 37-0 \%$ SBR

and $5,10,20 \%$ SBR
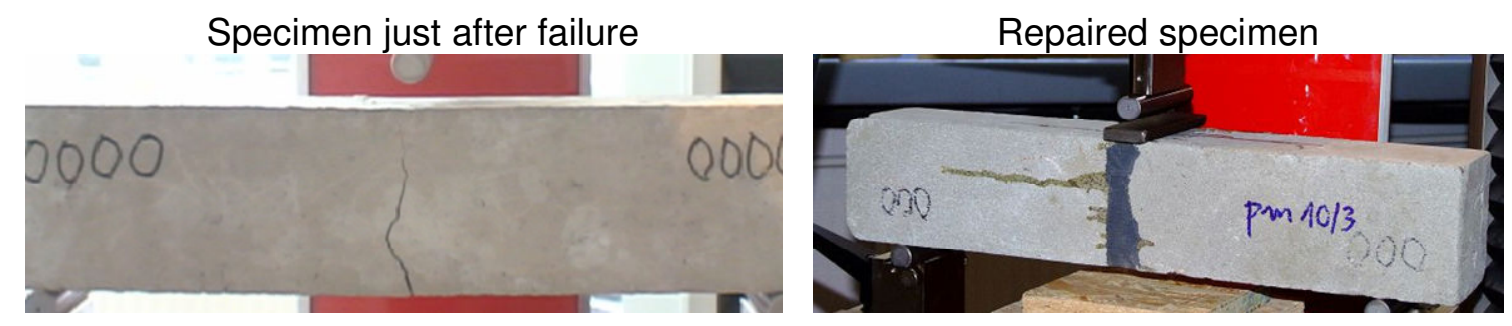

Figure 11. Three-point bending test on concrete specimens $(500 \times 100 \times 100 \mathrm{~mm})$. Tested specimen just after failure and after repair using of polymer flexible joint

Repair of damaged SBR concrete specimens using of epoxy resin and of the hard flexible polymer PT. According to the first approach, three pairs of specimens from each group of modified concrete (C5\%_1e and C5\%_1pt, C10\%_2e and C10\%_2pt, C20\%_3e and C20\%_3pt) were tested up to damage with measurements of force and vertical displacement (deflection). Obtained results are presented in form of force-displacement diagrams in Fig. 12a,b,c. Specimens repaired in each pair with the epoxy resin (e5_1, e5_2, e5_3) and the polymer PT (pt5_1, pt5_2, pt5_3) were tested also up to damage. Obtained results are presented as comparison in Fig. 12a,b,c. Every specimen was broken in concrete in a certain distance from the repair joint (Fig. 13a,b).

Comparison of obtained curves indicates that in the case of the cement-polymer composite modified using of SBR there is only small increase of strength capacity and deformability after repair using of the epoxy and the polymer PT. This kind of repair restores strength ability of cracked concrete and also of the cracked repair thin layer made of cement-polymer composites but do not protects a concrete floor against over-ultimate deformations, overcoming the ultimate strain angle $(\gamma$ $<0.5 \%$ ) of concretes and cement-polymer composites (Fig. 14). 
a)

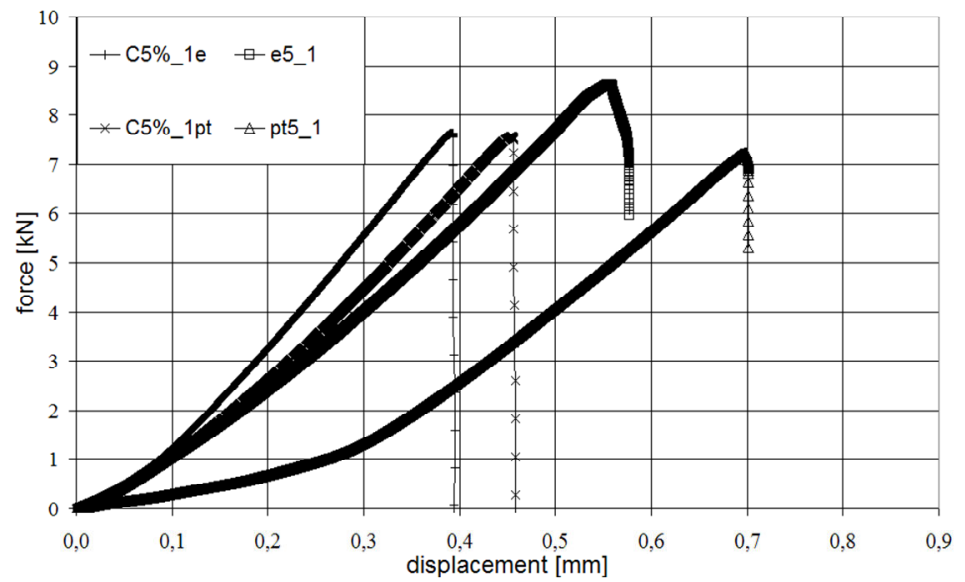

b)

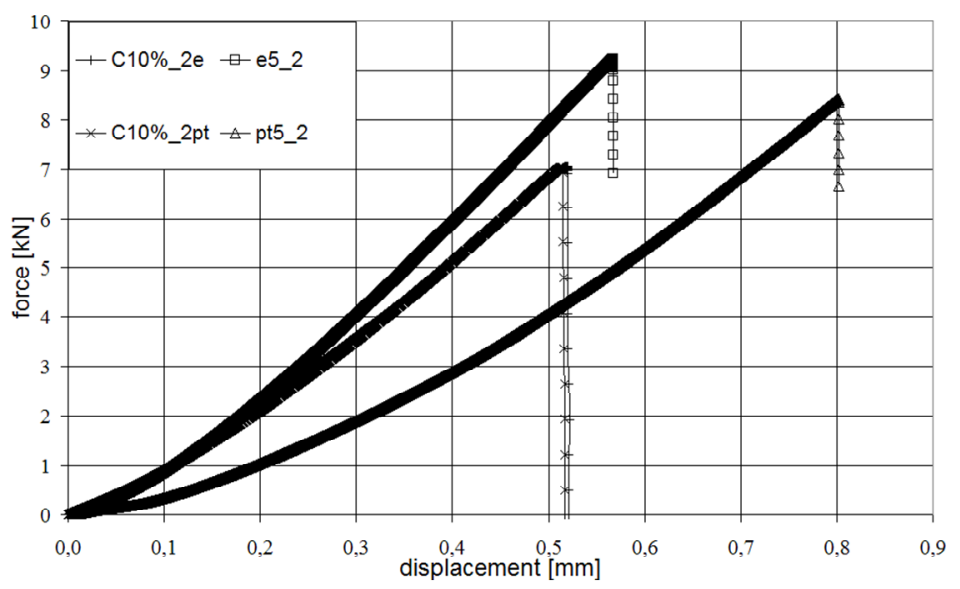

c)

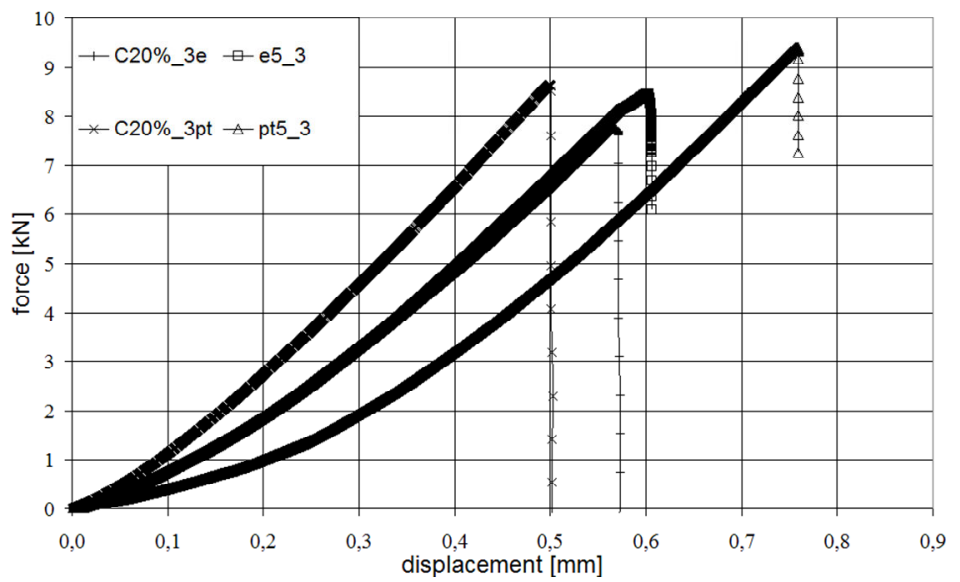

d)

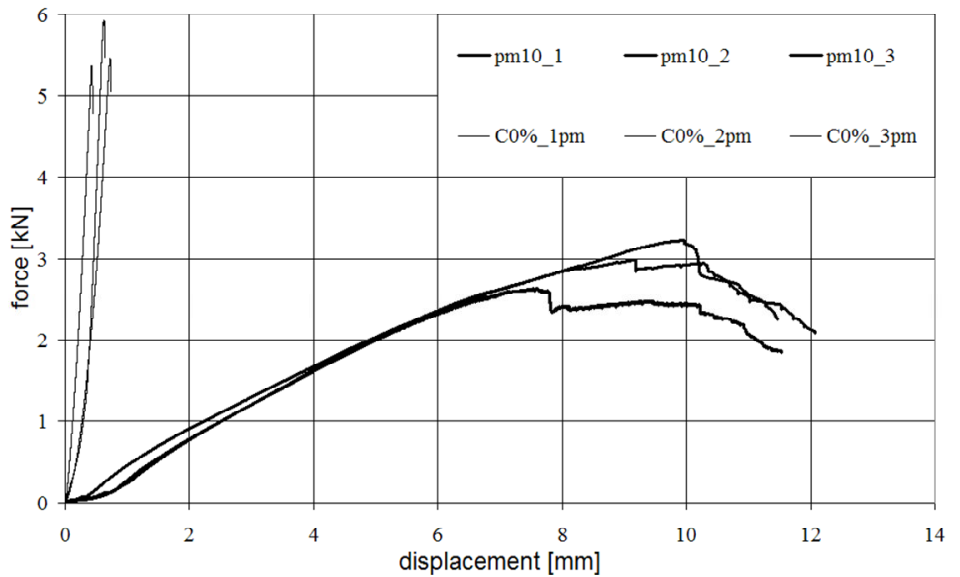

Figure 12. Comparison of bending curves obtained for original and repaired specimens for: (a) $5 \%$ SBR, (b) 10\% SBR, (c) 20\% SBR with epoxy and PT bonding and (d) 0\% SBR with PM bonding 

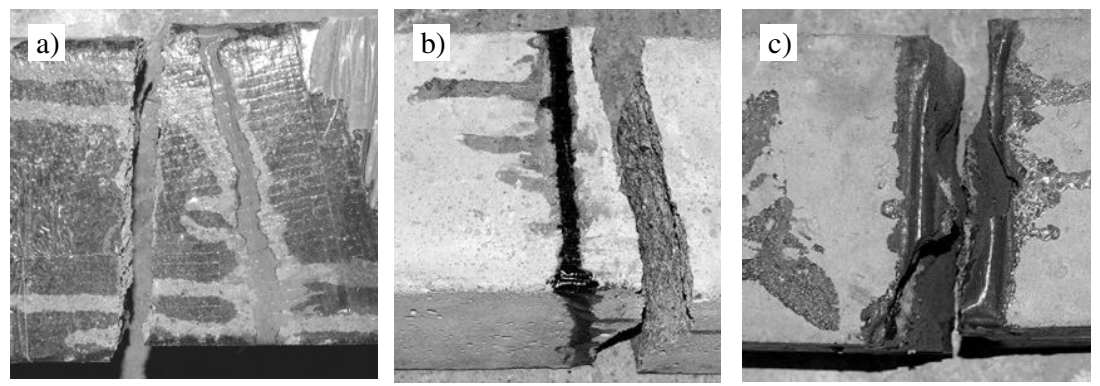

Figure 13. Forms of damage of specimens repaired using of: (a) epoxy resin Sikadur 53, (b) hard flexible polymer PT and (c) soft flexible polymer PM
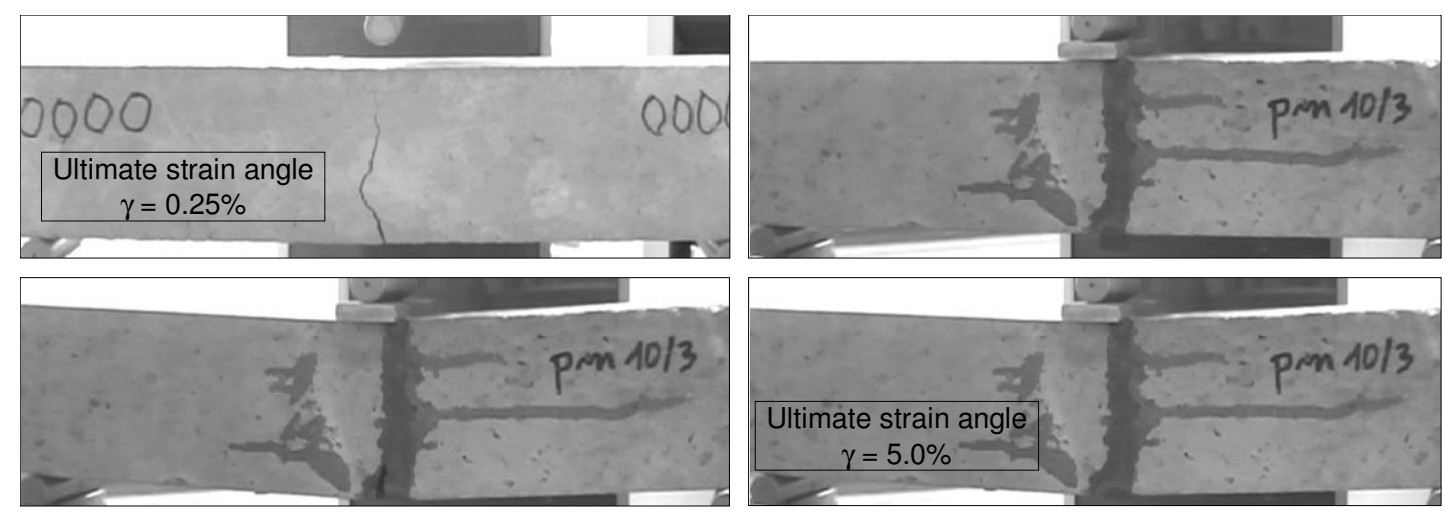

Figure 14. Comparison of ultimate strain angle in case of the original specimen and the repaired one using the soft flexible polymer PM

This conclusion confirms comparison of damage energy (calculated from diagrams in Fig. 12a,b,c) represented by area under the force-displacement curves and placed in Table 1. The values of damage energy before and after repair using of the epoxy and the polymer PT are comparable, giving energy ratio of the value 1.36 in the case of the epoxy joint and of the value of 1.51 in the case of the polymer PT joint. According to the ultimate strength, the repair of cementpolymer composites using of the polymer PT is not as advantageous as in the case of concrete without addition of SBR (Fig. 6).

Table 1. Comparison of damage energy of specimens bonded with epoxy and polymer

\begin{tabular}{|c|c|c|c|c|c|c|}
\hline \multicolumn{7}{|c|}{ Epoxy bonded specimen (e) Specimen } \\
\hline & & {$[\mathrm{J}]$} & {$[\mathrm{J}]$} & & {$[\mathrm{J}]$} & {$[\mathrm{J}]$} \\
\hline original & $\mathrm{C} 5 \% \_1 \mathrm{e}$ & 1.3 & \multirow{3}{*}{2.1} & C5\%_1pt & 1.5 & \multirow{3}{*}{1.8} \\
\hline repaired & e5_1 & & & pt5_1 & & \\
\hline original & $\mathrm{C} 10 \% \_2 \mathrm{e}$ & 1.7 & & $\mathrm{C} 10 \%+2 \mathrm{pt}$ & 1.7 & \\
\hline repaired & e5_2 & & \multirow[t]{2}{*}{2.4} & pt5_2 & & 2.9 \\
\hline original & C20\%_3e & 2.0 & & C20\%_3pt & 1.9 & \multirow[b]{2}{*}{3.0} \\
\hline repaired & e5_3 & & 2.3 & pt5_3 & & \\
\hline \multicolumn{2}{|c|}{ Mean value } & 1.67 & 2.27 & & 1.70 & 2.57 \\
\hline Ene & y ratio & 2.27 & $6[-]$ & & \multicolumn{2}{|c|}{$2.57 / 1.70=1.51[-]$} \\
\hline
\end{tabular}

Repair of damaged concrete specimens using of the soft flexible polymer PM. According to the second approach, three specimens of non modified concrete (C0\%_1pm, C0\%_2pm, C0\%_3pm) were tested up to damage as previously. Obtained results are presented in form of forcedisplacement diagrams in Fig. 12d. Specimens repaired using of the soft flexible polymer PM (pm10_1, pm10_2, pm10_3) were tested next up to damage. Obtained results are presented as comparison in Fig. 12d. Every specimen was broken in the flexible repair joint, without any destruction in original concrete (Fig. 13c). 
Comparison of obtained curves indicates that in the case of the repair using of the soft flexible polymer PM there is no increase of specimens' strength (it is assumed behavior in the second approach of flexible joint method) but there is huge increase of deformability (over 12 times Fig. 12d) and also of damage energy (over 18 times - Table 2). This kind of repair introduces new energy dissipaters in repaired concrete floors, which allow for withstanding even relatively huge deformations, because of the ultimate strain angle $(\gamma=5 \%$ - Fig. 14). In this case, the repair of concrete floors using of the soft flexible polymer PM is very effective, what was confirmed during over 3 years exploitation of cracked concrete airfield pavements, repaired using of flexible joint made of polymer PM [8].

Table 2. Comparison of damage energy of specimens bonded with flexible polymer PM $[1 \mathrm{~J}=1 \mathrm{Nm}]$.

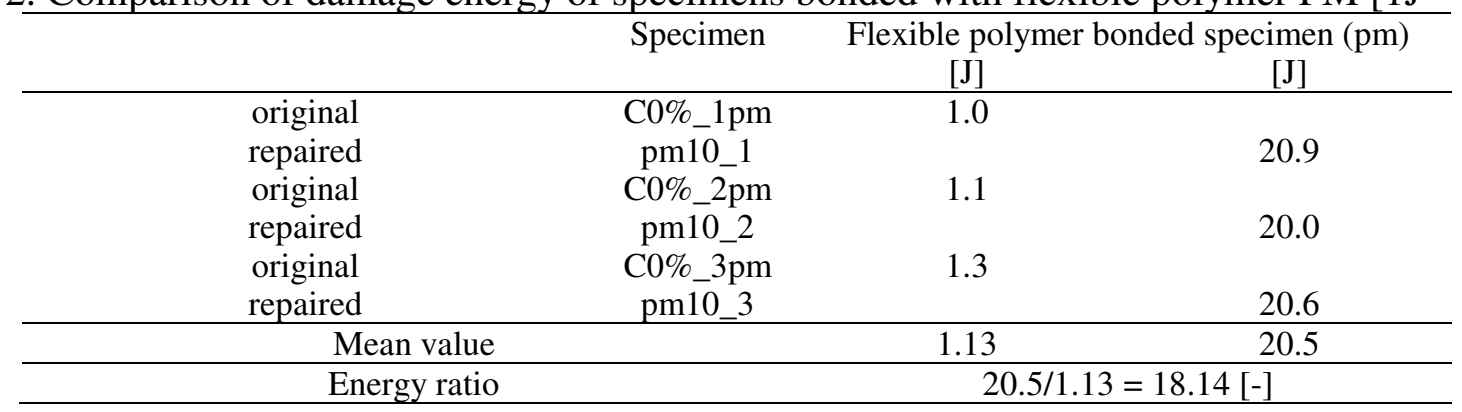

\section{Effectiveness of repair using of polymer flexible joint tested on airfield concrete pavements}

Repair of cracked concrete slab. A repaired cracked slab is localized at a taxiway in airport Krakow-Balice (KRK). It is a part of upper concrete layer (C40/45) of the JPCP of $0.22 \mathrm{~m}$ width, divided by joints (filled with bituminous sealant) into slabs of the diameter $5 \times 5 \mathrm{~m}$. The slab chosen for repair had cracks caused by acting of loading (aircraft) and warping (changing temperature) stresses, separating the slab corners (Fig. 15). The slab was repaired using of polymer flexible joints because of advantageous of the method and short time of application without necessity of the airport closing. The cracks were cut for the full depth outside of the slab and for the depth of $4 \mathrm{~cm}$ inside of it. After using of special primer, the holes were filled with the two-component polyurethane mass PM (Fig. 15).

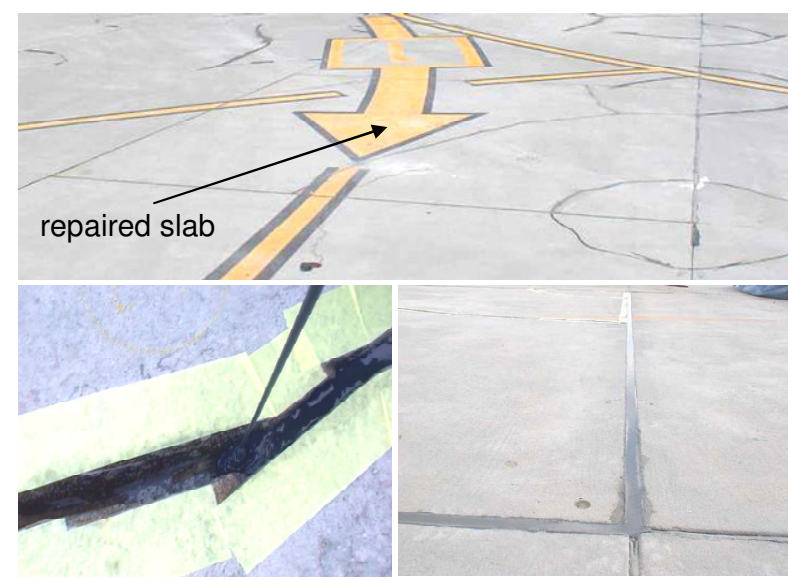

Figure 15. View of the airfield concrete slab repaired using flexible polymer joints with a visible map of cracks

Results of in situ tests on airfield pavements. Effectiveness of the innovative repair method was observed for over 3 years and tested using measurements for over one year. The polymer (PU) bonded slab and the not damaged one (with joints filled with bituminous mass) were chosen for comparison. Distribution of measure points, allowing measuring vertical and horizontal displacements of airfield slab edges and corners, was presented in [12] with detailed test results. 
Observations demonstrated that bonding of concrete slabs with polymer PM reduces vertical and horizontal deformations of them of about $50 \%$, allowing for safe work of airfield pavements. It should be noticed that contractions joints deform horizontally of about $5 \mathrm{~mm}$ between winter and summer and similar value was measured in cases of vertical deformation. An example of 24 hours measurements of vertical displacements of airfield slab is presented in Fig. 16 (for original slab with bituminous filling and slab bonded with polymer PM). Comparison of vertical displacement shows that the use of polymer joints in contradiction to bituminous mass reduces warping deformations of the corners about two times, what is very advantageous in aspect of airfield exploitation.
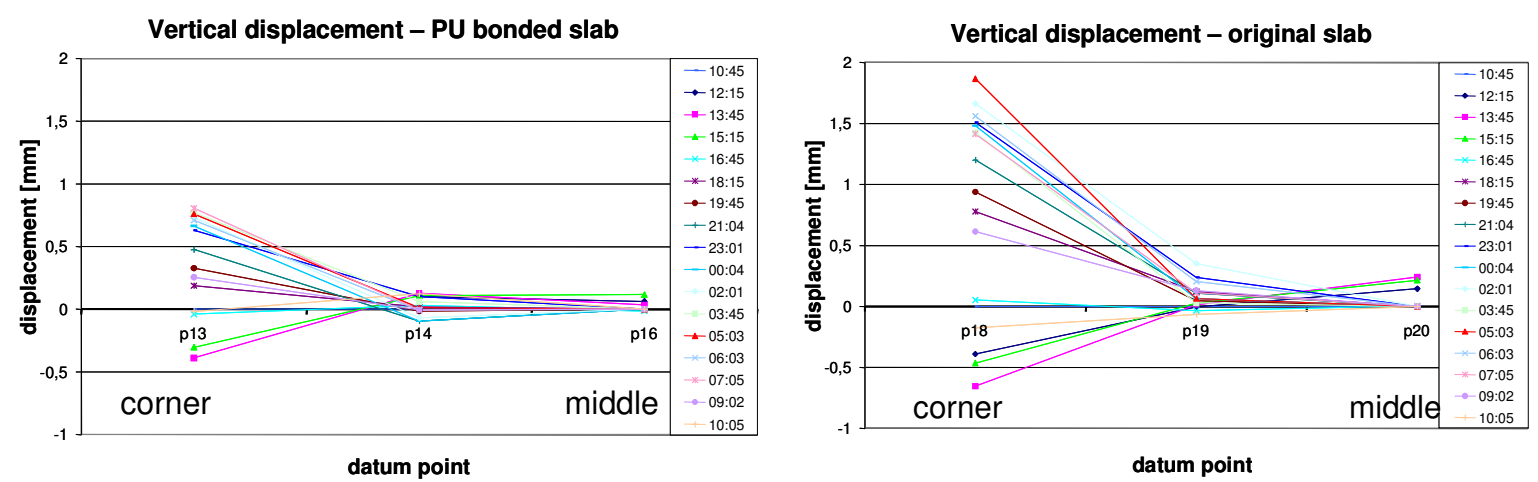

Figure 16. Results of 24 hours measurements of airfield slabs vertical displacements

The limitation of horizontal and vertical displacement of slab boundaries (or defragmented parts of a cracked slab) by polyurethane mass PM during warping deformation introduces small additional stress in concrete slabs of value under +/- 0.5 MPa. It is much lower than tensile strength of concrete but similarly a polymer joint introduces elastic cooperation between neighboring slabs. Cooperation allows for distributing of the aircraft gear load to other structural elements and causes reduction of loading stress in a critical cross-section of concrete slab [8].

Characteristic of polymer PM makes that the polyurethane mass works as a material of good dilatation properties. During winter, the polymer limits joints (cracks) expansion in opposite to bituminous mass, which does not work (displacement in case of polymer is 3-5 times lower [12]). During summer, the polymer allows for compression in its volume and free closing of a joint without squeezing filling mass out, as it occurs in the case of bituminous mass, see Fig. 17.
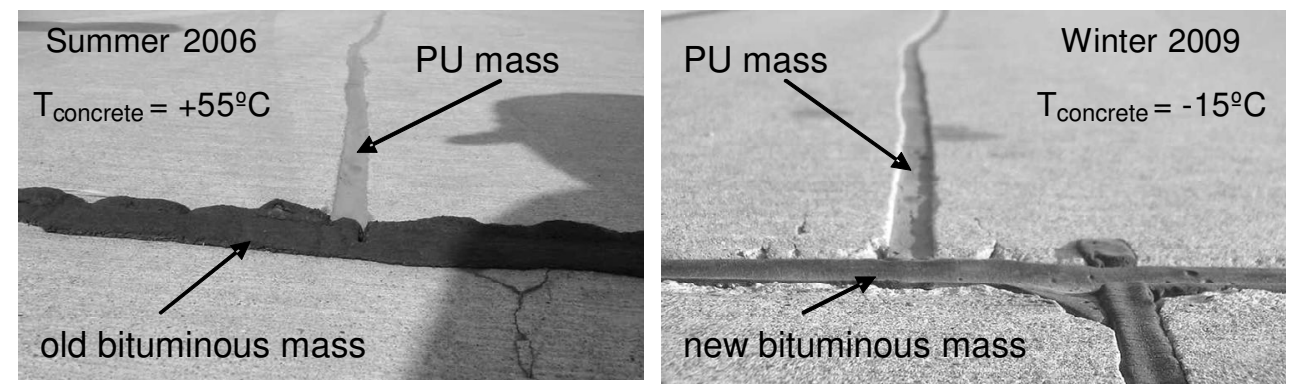

Figure 17. Effectiveness of the flexible polymer joint (in comparison to bituminous mass) observed in the runway of the KRK Airport during extreme temperatures of the concrete pavement surface

Moreover, PU mass is much more durable than bituminous mass and has much longer service life. Properties of polymer flexible joints constructed in repaired cracks and joints in the KrakowBalice Airport show that the polymer PM demonstrates very good strength and deformation conditions, high waterproof and reduces stress concentrations, protecting in this way concrete slabs against pressuring each other and caused by it appearing of new cracks and splinters. Observed polymer PM works properly in repair joints without any destruction or delamination in opposite to bituminous mass, which had to be changed in other places of application (Fig. 17). 
Calculation of polymer flexible joints. Considered polyurethane mass PM belong to the group of elastomeric materials, thus can be described using theory of the hyperelastic materials. In simple approach of this theory, properties of polymer mass are obtained from uniaxial tension and compression tests according to (Eq. 4), presented in [21]. Following equation (Eq. 4), the (Eq. 5) is proposed for calculation of uniaxial deformation of a flexible polymer joint.

$$
\begin{aligned}
& \sigma_{11}=\frac{\mathrm{P}}{\mathrm{A}_{0}}=\mathrm{E} \cdot \ln \left(\lambda_{1}\right) . \\
& \Delta \mathrm{s}=\left[\mathrm{e}^{\left(\frac{\sigma}{\mathrm{m} \cdot \mathrm{E}}\right)}-1\right] \cdot \mathrm{s} .
\end{aligned}
$$

where $\sigma_{11}=$ nominal stress for axial loading, $\mathrm{P}=$ the force of the specimen, $\mathrm{A}_{0}=$ the original area of the specimen, $\mathrm{E}=$ the Young's modulus, $\lambda_{1}=$ the uniaxial stretch ratio, $\Delta \mathrm{s}=$ change in the joint width, $\mathrm{s}=$ the started joint width, $\sigma=$ nominal stress caused by loading and $\mathrm{m}=$ the correction factor taking into account of polymer reological and cyclic loading aspects.

\section{Summary}

Considered repair methods of cracked concrete floors and pavements represent different properties. In cases of low deformations of repaired surface, where restoration of strength capacity and deformability of concrete is enough, there is efficient repair based on coating of cracked floor with thin layer made of cement-polymer composites with addition of SBR. In this new approach, polymer additives significantly reduce the shrinkage strains from concrete drying and increase bending strength.

The use of filling cracks with epoxy mass or with hard flexible polymer is also effective in the same case. Especially, repair of the cracked cement-polymer composites with addition of SBR is effective, because restores properties of floor concrete and also of the repair covering system. Unfortunately, both previously mentioned repair methods are inadequate in cases of large deformations, because of low value of the ultimate strain angle $(\gamma<0.5 \%)$. Overcome of this value causes appearing of new damage in concrete, close to the repair joint.

The very efficient repair method of cracked concrete floors in cases of large deformation is filling of cracks with soft flexible polymer. This kind of polymer introduces new energy dissipaters in repaired concrete floors, which allow for even relatively huge deformations, because of the ultimate strain angle $(\gamma=5 \%)$ and protects original concrete against repeated cracking.

This kind of elastomeric material was used in practical repair of cracked airfield concrete pavements (JPCP) in the Airport Krakow-Balice. Applied polymer PM minimize fatigue cracking of slabs by keeping stress at low level and minimize corner/joints deflection of rigid pavements, allowing for safe exploitation of concrete pavements. Construction of polymer joints and cure-time of PU mass is rapid, thus this repair method allows to keep the regulation given in the Airfield Pavement Repair \& Rehabilitation Mantra: "Get in as soon as possible, Do it right, Get out as quickly as possible, Stay out as long as possible".

\section{References}

[1] L. Czarnecki, L. Wolff: Defects and damage - electric methods. Industrial Floors, RILEM TC 184-IFE: State-of-the-Art Report, Chapter 3 (2006).

[2] H. Schorn, S. Gieler-Breßmer, M. Raupach:. Repair. Industrial Floors, RILEM TC 184-IFE: State-of-the-Art Report, Chapter 5 (2006).

[3] W. Wu, T. Chen, W. Zang, R. Chen: Study of the causes of crack in concrete pavement of airfield. RILEM Proceedings PRO 32, Advances in concrete and structures, ICACS 2003, Xuzhou, (2003). 
[4] M.F.M. Zain, H.B. Mahmud, A. Ilham, M. Faizal: Prediction of splitting tensile strength of high-performance concrete. Cement and Concrete Research 32 (2002) 1251-1258.

[5] T.F. Fwa, (ed.): Handbook of highway engineering. CRC Press, Taylor \& Francis Group (2006).

[6] J.W. Ju, Y. Zhang: Axisymmetric thermomechanical constitutive and damage modeling for airfield concrete pavement under transient high temperature. Mechanics of Materials 29 (1998) 307-323.

[7] A. Kwiecień: Damages of airfields pavements made of concrete (in Polish). Proceedings of XXIV Conference Structural Failures 2009, pp. 481 - 488, Międzyzdroje.

[8] A. Kwiecień, B. Zając, W. Czyczuła, D. Kudła: Analysis of work of cracked concrete pavements basing on investigations of airfield slabs repaired using of a polymer joint (in Polish). Przegląd Komunikacyjny 4/2008, Wyd. SITK, pp. 29 - 40.

[9] P. Cognard: Technical Characteristics and Testing Methods for Adhesives and Sealants. Adhesives and Sealants Basic Concepts and High Tech Bonding Vol. 1, Elsevier (2005).

[10] A. Kwiecień, B. Zając, R. Jankowski: Static and dynamic properties of a flexible joint working in cracked historical masonries. Proceedings of Structural Analysis of Historical Constructions VI, Bath, (2008).

[11]A. Kwiecień, B. Zając: Dynamic response of the cracked masonry building repaired with the Flexible Joint Method - an innovative earthquake protection. Proceedings of 7th European Conference on Structural Dynamics EURODYN'2008, Southampton, (2008).

[12]A. Kwiecień: New repair method of cracked concrete airfield surfaces using of polymer joints. 13th Int. Congress on Polymers in Concrete ICPIC 2010, pp. 657 - 664.

[13]A. Kwiecień: Conception of the use of polymer flexible joint in bridges (in Polish). Inżynieria i Budownictwo, No. 5/2009, pp. 268 - 272.

[14]A. Kwiecień: Polymer flexible joints - an innovative repair system protecting cracked masonries against stress concentrations. Proceedings of Protection of Historical Buildings, PROHITECH 09, Mazzolani (ed), Taylor \& Francis Group, Vol.2, pp. 1033-1038, London, (2009).

[15]Z. Su: Microstructure of polymer-cement concrete. Delft University Press, (1995).

[16] A. Kwiecień, M. Gruszczyński, B. Zając: Tests of flexible polymer joints repairing of polymer modified concretes. 13th Int. Congress on Polymers in Concrete ICPIC 2010, pp. 559 - 566.

[17]Z. Su, J.M. Bijen, J.A. Larbi: Influence of polymer modification on the hydration of portland cement. Cement Concrete Research 21/1991, pp. 535-544.

[18]S. Okba, A. El-Dieb, M. Reda: Investigations of the sulphate resistance of polymer-modified mortar. 10th Int. Congress on Polymers in Concrete, Hawaii, (2001).

[19] S. Schwarz: Research of structures of polymer-modified mortars. 4th Int. Congress on Polymers in Concrete, Darmstadt, (1984).

[20] S. Popovics: Polymers for modification of P.C. concrete in USA. 7th Int. Congress on Polymers in Concrete, Moscow, (1992).

[21]Z. Nowak, 2007. Constitutive modeling and parameter identification for rubber-like materials. Engineering Transactions, vol. 55, No.4. 